\title{
DESIGNING IN A CROSS-CULTURAL CONTEXT: AN ANALYSIS OF BRAZILIAN, ITALIAN, JAPANESE AND TURKISH STUDENTS' DESIGN METHODS
}

\author{
Claudia NICHETTI ${ }^{1}$, Roberta BERTOLETTI ${ }^{1}$, Julio VAN DER LINDEN ${ }^{1}$, Erik BOHEMIA², \\ Pinar KAYGAN ${ }^{3}$ and Mauricio BERNARDES ${ }^{1}$ \\ ${ }^{1}$ Universidade Federal do Rio Grande do Sul - UFRGS \\ ${ }^{2}$ Academy of Design Innovation Management - ADIM \\ ${ }^{3}$ Middle East Technical University - METU
}

\begin{abstract}
The objective of this article is to analyse the relationship between the use of methods and processes used in the local mobility projects of Global Studio 2018. The Global Studio is an annual project that promotes the exchange between groups with different cultures and that covers different countries. In 2018, the proposed theme was solutions for local mobility and the countries involved are Brazil, Italy, Japan and Turkey. For this, projects developed in the disciplines of the design course were analysed with graduates of design courses of different universities. The methodology includes analysis of the records of the processes and methods used, stories in the blogs and analysis of the proposals developed by the students. The data obtained was analysed qualitatively and quantitatively. Based on parameters adopted for this study it was possible to generate a score that represents the level that each team fulfilled the tasks to reach its design solution. Comparing the teams scores it was possible to identify a pattern that suggests that interactions between teams have relevant effects on each team performance.
\end{abstract}

\section{Keywords: Design methods, design education, global studio, cross-cultural context, mobility}

\section{INTRODUCTION}

Global Studio is an annual project developed since 2007 and aims to develop skills for students to work in teams through the exchange between universities of different countries and cultures [1]. In the edition of the Global Studio of 2018, the theme proposed to the teams of the participating universities (Brazil, Italy, Japan and Turkey) was to design solutions for local mobility, considering the ways in which people move in different parts of the world. For the challenge, the teams were proposed a design process model in five phases: briefing, concept, detail, testing and prototype and presentation of the result. To propose innovative solutions, the teams simulated situations that the design offices face on a day-to-day basis. That is, understanding the customer's need, limited time for development, demand for product quality, understanding the local culture and urban scenario, amongst other factors that added complexity to the project. In a context that seeks to develop innovative solutions, it is important to use methods, strategies and tools that help the activities of designers and teams [2]. The set of methods used in a particular job is called methodology. The methodology, in turn, in design aims to provide a structure that supports the designer in solving problems in different projects, contexts and environments [3]. Therefore, to start a project, there is a pattern that the designer or project team uses to solve a problem or perform a readjustment. If it is about mobility projects for cities, the set of methods must consider the cultural context of the place, the characteristics of the urban space and understand the behaviour of the user.

Regarding the cultural context, it is possible to affirm that the expression of culture manifests itself on different levels and in different ways [4], and to the culture of design, in a certain way it is dependent on how culture, a nation or an organisation, is established. The different manifestations of culture influence the performance of the designer, thus explaining the existence of different design models. Therefore, the macro context influences the design models that, in turn, influence the results of the conceived works [5]. Culture affects behaviour and interpretations of behaviour [4]. Although certain aspects of culture are physically visible, their meaning is invisible, that is, the meaning that a gesture can have for a cultural context can be interpreted differently by another. For example, a gesture such as 
pointing with a thumb may be interpreted as a transportation agreement, approval or acceptance in the United States, the United Kingdom and Canada, but as an insulting or obscene gesture in several Mediterranean countries. In the same way, the choice of clothing can be interpreted differently by different groups of people; indicating social class, ostentation, adequacy and so on [4].

With regard to the physical characteristics of the urban space and the behaviour of the people, it is known that the built environment affects the behaviour of individuals and vice versa, so that it is necessary to produce knowledge that helps in understanding the psychological and behaviour of the people in relation to the space, generating subsidies for projects more adapted to the needs of the users of these spaces. The evaluation of the physical environment is performed by means of processes of perception and cognition, based on the knowledge of the image formed by the users and using the satisfaction and the behaviour of the individuals as indicators of performance of the spaces [6]. Yet, the environment generates information, which is identified by our body through the senses (sight, hearing, smell, taste, and touch) [7], [8]. Thus, cities are described, analysed and evaluated, which makes this process an important part of the design methods when we talk about urban mobility projects.

Design methods are used in the design process to help make decisions, mainly in projects with a specific time frame and that require quality in the solution and efficiency in the design process. However, its use is not always done by designers and that is due to several reasons. Therefore, it is necessary to deepen the knowledge about the impact of the use or non-use of methods to solve problems in different contexts and cultures; and how much that factor is decisive in the quality of the results. In the event that the development environment is academic and that students have knowledge in design methodology, it is not always used in projects, and it is rarely used in a simplified way, from analysis or in creative processes. In this sense, the objective of this article is to analyse the methods and processes used to address the challenge proposed by the Global Studio 2018 to improve local mobility by the students of the four universities involved in the challenge.

\section{METHODOLOGICAL PROCEDURES}

The collaborative design project involved five universities from four countries (Brazil, Italy, Japan and Turkey) and was developed in undergraduate disciplines of design courses for a period of 10 weeks. During the Global Studio project, the participating students realised at the same time the role of client and team of designers among the countries. Table 1 presents the proposed design process, according to the Global Studio documents.

Table 1. Proposed design process

\begin{tabular}{|l|l|l|l|}
\hline Stage & Description & Designer & Client \\
\hline 1 & Design Brief & Clarify & Research/Write \\
\hline 2 & Design Concepts & Develop & Evaluate \\
\hline 3 & Detail Design & Construct & Evaluate/clarify \\
\hline 4 & Prototypes and Testing & - & Build and test \\
\hline 5 & Presentation & - & Feedback (reflection) \\
\hline
\end{tabular}

In addition, the briefing also provided information about the users and the context of the city / country where the equipment was located. The central theme of the project is to develop solutions for local mobility. The students interacted through blogs (WordPress) and Skype.

In total 26 students were allocated into 16 project teams. The project teams were formed from students co-located within each of the participating universities, and each team was allocated a specific project blog. These blogs were customised by the project teams and were used by them to post as when undertaking design tasks. The paired team located at another university who worked as clients and provided information and comments for the designers.

The data used for this study was collected in the posts of the students in the teams' blogs. The important posts of the blog were selected randomly and observed by the authors. The specific numbers of the entries of each blog are presented in Table 2 (the comments of the speakers and the presentation of the same ones were not included in the count). The observation focused on the identification of the following questions: a) how the students appropriated the methods for the development of the projects; b) how the design students produced design concepts considering the cultural differences between the countries; and finally, c) how the students analysed the urban context and local mobility difficulties. 
Table 2. Paired teams

\begin{tabular}{|l|l|l|l|l|l|l|}
\hline (Team) Country & $\begin{array}{l}\text { Qty. } \\
\text { students }\end{array}$ & $\begin{array}{l}\text { Qty. } \\
\text { posts }\end{array}$ & $\begin{array}{l}\text { Paired } \\
\text { teams }\end{array}$ & $\begin{array}{l}\text { (Team) } \\
\text { Country }\end{array}$ & $\begin{array}{l}\text { Qty. } \\
\text { students }\end{array}$ & $\begin{array}{l}\text { Qty. } \\
\text { posts }\end{array}$ \\
\hline (1) Turkey & 2 & 15 & $1-7$ & (7) Japan & 7 & 13 \\
\hline (2) Turkey & 2 & 15 & $2-8$ & (8) Japan & 6 & 20 \\
\hline (3) Turkey & 2 & 13 & $3-9$ & (9) Italy & 6 & 28 \\
\hline (4) Turkey & 3 & 15 & $4-10$ & (10) Brazil Unisinos & 3 & 16 \\
\hline (5) Turkey & 3 & 15 & $5-11$ & (11) Brazil UFRGS & 3 & 4 \\
\hline (6) Turkey & 3 & 15 & $6-12$ & (12) Brazil UFRGS & 3 & 16 \\
\hline (13) Turkey & 2 & 16 & $13-15$ & (15) Italy & 5 & 21 \\
\hline (14) Japan & 9 & 12 & $14-16$ & (16) Brazil UFRGS & 2 & 14 \\
\hline Total & $\mathbf{2 6}$ & $\mathbf{1 1 6}$ & & & $\mathbf{3 5}$ & $\mathbf{1 3 2}$ \\
\hline Total no students & 61 & & Total no posts & 248 & \\
\hline
\end{tabular}

Elaborated by the authors

For the analysis of the methods used by the student's parameters were established synthesised in 5 stages, according to Table 3 . The parameters serve to verify whether or not these design process stages were contemplated by the students in the development of the solutions. The obtained data was analysed qualitatively and later generated binary scores: $1=$ Yes, performed the task and $0=\mathrm{No}$, did not perform the task. In the case of Design Brief (step 1) a variable was included that does not refer to a task, but to the attention of the demand to address an urban mobility problem.

Table 3. Analysis parameters

\begin{tabular}{|l|l|l|}
\hline Stage & Description & Tasks \\
\hline 1 & Design Brief & Collection of data and photos of the urban scene \\
& & Data collection and mobility photos \\
& & Collection of cultural context data \\
& & Analysis of user behaviour \\
& & description of the problem \\
& & The central problem is urban mobility? \\
\hline 2 & Design Concepts & Analysis \\
\hline 3 & Detail Design & List of requirements \\
& & Generation and evaluation of alternatives \\
& & Feedback \\
& & Technical detail \\
\hline 4 & Prototypes and Testing & Digital prototype \\
\hline 5 & Presentation & Physical prototype \\
& & Final presentation \\
& & Final Feedback \\
\hline
\end{tabular}

Adapted by the authors based on the Global Studio proposal

\section{RESULTS AND DISCUSSION}

\subsection{Design Brief}

The scenarios provided by the teams should provide information such as: photos and data of the urban scenario, photos and data on mobility in the city, cultural context, clear description of the problem and user behaviour. In addition, the central problem should solve a mobility problem in the city.

Among the 16 teams, only 3 (18\%) addressed what was expected for this stage, offering their paired teams all the data necessary for the development of the project. On the other hand, 15 (94\%) briefings informed in a clear and objective way the problem to be solved. With regard to information on the cultural context, $6(36 \%)$ of the briefings considered this information and $5(31 \%)$ had data and photos of the urban scenario. The methods used by the teams for the collection of information data, such as interviews with users, were not identified in the briefings. The information on user behaviour, provided by 12 teams ( $75 \%$ ), was made through photos, possibly via Internet search, and brief stories by the client team. 
Table 4. Information available in the briefings

\begin{tabular}{|c|c|c|c|c|c|c|c|}
\hline Team & $\begin{array}{c}\text { Urban scene } \\
\text { data and } \\
\text { photos }\end{array}$ & $\begin{array}{c}\text { Mobility } \\
\text { data and } \\
\text { photos }\end{array}$ & $\begin{array}{c}\text { Cultural } \\
\text { context } \\
\text { data }\end{array}$ & $\begin{array}{c}\text { User } \\
\text { behaviour }\end{array}$ & $\begin{array}{c}\text { Problem } \\
\text { description }\end{array}$ & $\begin{array}{l}\text { Problem } \\
\text { is urban } \\
\text { mobility }\end{array}$ & Note \\
\hline Team 1 (TUR) & 1 & 1 & 0 & 0 & 1 & 1 & - \\
\hline Team 2 (TUR) & 0 & 1 & 0 & 0 & 1 & 0 & Tourism \\
\hline Team 3 (TUR) & 1 & 1 & 1 & 1 & 1 & 1 & - \\
\hline Team 4 (TUR) & 0 & 1 & 0 & 1 & 0 & 0 & Security \\
\hline Team 5 (TUR) & 0 & 0 & 0 & 1 & 1 & 0 & Leisure \\
\hline Team 6 (TUR) & 0 & 1 & 0 & 1 & 1 & 1 & - \\
\hline Team 7 (JPN) & 1 & 1 & 1 & 1 & 1 & 1 & - \\
\hline Team 8 (JPN) & 0 & 0 & 0 & 0 & 1 & 1 & - \\
\hline Team 9 (ITA) & 1 & 1 & 1 & 1 & 1 & 1 & - \\
\hline Team 10 (BRA) & 0 & 1 & 1 & 1 & 1 & 0 & Social \\
\hline Team 11 (BRA) & 0 & 1 & 0 & 1 & 1 & 1 & - \\
\hline Team 12 (BRA) & 1 & 1 & 1 & 0 & 1 & 1 & - \\
\hline Team 13 (TUR) & 0 & 1 & 0 & 0 & 1 & 1 & - \\
\hline Team 14 (JPN) & 0 & 0 & 0 & 0 & 1 & 1 & - \\
\hline Team 15 (ITA) & 0 & 0 & 1 & 0 & 1 & 1 & - \\
\hline Team 16 (BRA) & 0 & 1 & 0 & 1 & 1 & 1 & - \\
\hline Total & $5(31,2 \%)$ & $12(75 \%)$ & $6(37,5 \%)$ & $9(56,2 \%)$ & $15(93,7 \%)$ & $12(75 \%)$ & \\
\hline
\end{tabular}

Note: $1=$ Yes, answered the task and $0=$ No, did not answer the task

Regarding the briefings, only three of the six items in Table 4 provided the necessary information for the development of the project as expected, with percentages of $75 \%$ and $93.7 \%$. For the other items, the teams should have provided more information, mainly on data and photos of the urban scenario and the cultural context (percentages below 40\%). This suggests a lack of attention to important issues.

\subsection{Design Concepts and Detail Design}

In the second and third stages of the design process - Design Concepts and Detail Design - information should be provided on the analysis, list of requirements, generation and evaluation of alternatives, customer feedback and technical detail. The obtained data was synthesised in Table 5, below. It is observed that amongst the 16 teams, only teams 3, 7,9 (18.7\%), provided all the important information for these stages. Analyses were performed by 11 teams $(68.7 \%)$. The list of requirements was made by 9 teams (56.2\%). The generation and evaluation of the alternatives and the feedback of the client were informed by all the teams. Finally, the technical detail was presented by $81.2 \%$ ( 13 teams).

Table 5. Synthesis of the phases Design concepts e Detail Design

\begin{tabular}{|c|c|c|c|c|c|}
\hline Team & Analysis & $\begin{array}{c}\text { List of } \\
\text { requirements }\end{array}$ & $\begin{array}{c}\text { Generation and } \\
\text { evaluation of } \\
\text { alternatives }\end{array}$ & $\begin{array}{l}\text { Customer } \\
\text { Feedback }\end{array}$ & $\begin{array}{c}\text { Technical } \\
\text { detail }\end{array}$ \\
\hline Team 1 (TUR) & 0 & 1 & 1 & 1 & 1 \\
\hline Team 2 (TUR) & 1 & 0 & 1 & 1 & 1 \\
\hline Team 3 (TUR) & 1 & 1 & 1 & 1 & 1 \\
\hline Team 4 (TUR) & 0 & 0 & 1 & 1 & 1 \\
\hline Team 5 (TUR) & 1 & 0 & 1 & 1 & 1 \\
\hline Team 6 (TUR) & 1 & 1 & 1 & 1 & 1 \\
\hline Team 7 (JPN) & 1 & 1 & 1 & 1 & 1 \\
\hline Team 8 (JPN) & 1 & 1 & 1 & 1 & 0 \\
\hline Team 9 (ITA) & 1 & 1 & 1 & 1 & 1 \\
\hline Team 10 (BRA) & 0 & 0 & 1 & 1 & 0 \\
\hline Team 11 (BRA) & 1 & 1 & 1 & 1 & 1 \\
\hline Team 12 (BRA) & 1 & 1 & 1 & 1 & 1 \\
\hline Team 13 (TUR) & 1 & 0 & 1 & 1 & 1 \\
\hline Team 14 (JPN) & 0 & 0 & 1 & 1 & 0 \\
\hline Team 15 (ITA) & 1 & 1 & 1 & 1 & 1 \\
\hline Team 16 (BRA) & 0 & 0 & 1 & 1 & 1 \\
\hline Total & $11(68,7 \%)$ & $9(56,2 \%)$ & $16(100 \%)$ & $16(100 \%)$ & $13(81,2 \%)$ \\
\hline
\end{tabular}

Note: $1=$ Yes, answered the task and $0=$ No, did not answer the task 
The data obtained in the stages of concept design and design detail (Table 5) can indicate a greater commitment and immersion of the teams. This is evident when comparing the percentages of the data obtained in the briefing stage (Table 4).

\subsection{Prototypes, testing and presentation}

The synthesis of the stages of prototypes, testing and presentation are organised in Table 6 . The teams should create digital and physical prototype. In the next step they should test and evaluate the products generated. And in the end, present the final results and show the final feedback.

Amongst the 16 teams involved in the challenge, 13 teams (81.2\%) developed a digital prototype, however only half of these teams tested the products they generated. The physical prototypes were created by 9 teams (56.2\%) and only one of the teams did not test. In addition, 8 teams (50\%) developed both the physical prototype and the digital prototype. And yet, observing the information available in the communication channels, two teams ( 8 and 14 ) did not create prototypes and, consequently, did not perform the tests.

For the presentation stage, the teams made available videos or files in different formats (PDF, JPG, PPT) with the construction of the prototype until the end of the product. The schedules of presentations, according to the difference of time zone, were programmed previously with the teams.

At the end of the stages of presentation of the final result and of the final feedback, it is perceived that the data reported was satisfactory (75\% and $81.2 \%)$. Only one team (Team 14) did not provide information on these steps. Therefore, it is considered that the team gave up the task and did not complete the challenge.

Table 6. Synthesis of the phase's prototypes, testing and presentation

\begin{tabular}{|l|c|c|c|c|}
\hline \multicolumn{1}{|c|}{ Team } & Digital prototype & $\begin{array}{c}\text { Physical } \\
\text { prototype }\end{array}$ & Tests & $\begin{array}{c}\text { Final result } \\
\text { presentation }\end{array}$ \\
\hline Team 1 (TUR) & 1 & 0 & 0 & 1 \\
\hline Team 2 (TUR) & 1 & 0 & 0 & 1 \\
\hline Team 3 (TUR) & 1 & 1 & 0 & 1 \\
\hline Team 4 (TUR) & 1 & 1 & 0 & 0 \\
\hline Team 5 (TUR) & 1 & 0 & 1 & 1 \\
\hline Team 6 (TUR) & 1 & 1 & 1 & 1 \\
\hline Team 7 (JPN) & 1 & 1 & 0 & 0 \\
\hline Team 8 (JPN) & 0 & 0 & 1 & 1 \\
\hline Team 9 (ITA) & 1 & 1 & 1 & 1 \\
\hline Team 10 (BRA) & 1 & 0 & 1 & 1 \\
\hline Team 11 (BRA) & 0 & 1 & 1 & 1 \\
\hline Team 12 (BRA) & 1 & 1 & 0 & 1 \\
\hline Team 13 (TUR) & 1 & 1 & 1 & 1 \\
\hline Team 14 (JPN) & 0 & 0 & 0 & 1 \\
\hline Team 15 (ITA) & 1 & 1 & $\mathbf{8}(\mathbf{5 0 \% )}$ & 1 \\
\hline Team 16 (BRA) & 1 & $\mathbf{9 ( 5 6 , 2 \% )}$ & $\mathbf{1 2}(\mathbf{7 5 \% )}$ & 1 \\
\hline Total & $\mathbf{1 3}(\mathbf{8 1 , 2 \% )}$ & $\mathbf{1 3}(\mathbf{8 1 , 2 \% )}$ \\
\hline
\end{tabular}

Note: $1=$ Yes, answered the task and $0=$ No, did not answer the task

\subsection{Design process and team interactions}

By means of Table 7 it is possible to summarise the results considering teams performance and interactions between teams. The Global Studio is based on a peer learning approach therefore it is expected that good interactions between paired teams result on good learning experiences. Results from each stage were summed and results were converted to percentage. Three teams reached the higher score according to the parameters adopted for this study. Two of them, teams 6 and 9 worked as paired teams; the other one, team 7 worked with team 1 that obtained a medium-high score. Five other teams obtained also medium-high scores, four of them worked as paired teams (6 and 12;13 and 15). Only in one case a team had a medium-high score working with a team that had a medium-low score (11 and 5, respectively). 
Table 7. Paired teams and their scores

\begin{tabular}{|c|c|c|c|c|c|c|c|c|c|}
\hline \multirow{2}{*}{$\begin{array}{l}\text { (Team) } \\
\text { Country }\end{array}$} & \multicolumn{3}{|c|}{ stages } & \multirow{2}{*}{$\begin{array}{l}\text { Score } \\
\text { (percent) }\end{array}$} & \multirow{2}{*}{$\begin{array}{l}\text { (Team) } \\
\text { Country }\end{array}$} & \multicolumn{3}{|c|}{ stages } & \multirow{2}{*}{$\begin{array}{l}\text { Score } \\
\text { (percent) }\end{array}$} \\
\hline & 1 & $2 / 3$ & $4 / 5$ & & & 1 & $2 / 3$ & $4 / 5$ & \\
\hline (1) Turkey & 4 & 4 & 3 & $11(68,8 \%)$ & (7) Japan & 6 & 5 & 5 & $16(100 \%)$ \\
\hline (2) Turkey & 2 & 3 & 3 & $8(50 \%)$ & (8) Japan & 2 & 4 & 1 & $7(43,3 \%)$ \\
\hline (3) Turkey & 6 & 5 & 5 & $16(100 \%)$ & (9) Italy & 6 & 5 & 5 & $16(100 \%)$ \\
\hline (4) Turkey & 2 & 3 & 5 & $10(62,5 \%)$ & (10) Brazil & 4 & 2 & 3 & $9(52,3 \%)$ \\
\hline (5) Turkey & 2 & 4 & 1 & $7(43,3 \%)$ & (11) Brazil & 4 & 5 & 4 & $13(81,35)$ \\
\hline (6) Turkey & 4 & 5 & 5 & $14(87,5 \%)$ & (12) Brazil & 5 & 5 & 5 & $13(81,35)$ \\
\hline (13) Turkey & 3 & 4 & 5 & $12(75 \%)$ & (15) Italy & 3 & 5 & 5 & $13(81,35)$ \\
\hline (14) Japan & 2 & 3 & 0 & $5(31,3 \%)$ & (16) Brazil & 4 & 3 & 1 & $8(50 \%)$ \\
\hline
\end{tabular}

\section{FINAL CONSIDERATIONS}

Parameters used for this study were defined in order to realise an objective analysis of a complex phenomenon. Follow a design method or go through a design process involves, at least, cultural, educational and personal issues. Previous experience and motivation may conduct a team to reach its goal. Lack of confidence and technical barriers may conduct a team to failure and defeatism. For 10 weeks students from five universities at four countries dealt with a challenge that involved technical and social skills. This work is an attempt to analyse these teams design processes by means of parameters that allow to quantify how each team performed concerning a methodological and theoretical points of view. Based on each team results and on its paired team results it could be suggested that interactions between teams might have relevant effects on their scores. In depth interviews could be useful to explore and clarify these effects in future studies.

\section{REFERENCES}

[1] Hong B. B., Bohemia E., Neubauer R. and Santamaria L. Designing for Users: The Global Studio. In: Proceedings of the International Conference on Engineering and Product Design Education. Dyson School of Design Engineering, Imperial College, London, United Kingdom. 2018.

[2] Stetter R. and Lindemann U. The transfer of methods into industry. In: J. Clarkson; C. Eckert (Eds.); Design process improvement, 2005 (Springer, London)..

[3] Badke-Schaub P., Daalhuizen J. and Roozenburg N. Towards a Designer--Centred Methodology: descriptive considerations and prescriptive reflections. In: BIRKHÖFER, H. (Ed.) The Future of Design Methodology. 2011, (Springer, London).

[4] Spencer-Oatey H. What is culture. GlobalPAD Core Concepts, 2012.

[5] Erez M. Culture and job design. Journal of Organisational Behaviour, 2010, 31( 2-3), 389-400.

[6] Lay M.C.D., Reis A.T.L., Dreux V., Becker D. and Ambrosini V.C. Spatial Configuration, Spatial Behaviour and Spatial Cognition: Syntactic and Perceptual Analysis of the Market Station Area in Porto Alegre. In: Proceedings of the Thirty-sixth Annual Conference of the Environmental Design Research Association. Edmond, Oklahoma: EDRA, 2005. v. 1. p. 129-136.

[7] Gibson J.J. The senses considered as perceptual systems, 1996 (Greenwood Press, Westport).

[8] Golledge R.G. and Stimson R.J. Spatial Behaviour, 1997 (The Guilford Press, New York). 